\title{
VENEZUELA 2002: \\ CRISIS POLÍTICA Y DERECHO
}

\author{
ROGELIO PÉREZ PERDOMO
}

Profesor del Instituto de Estudios Superiores de Administración Caracas 


\section{SUMARIO}

Chávez, la Constitución y la bicha - El otoño del patriarca. - La fuerZA Y LOS LIMMITES DEL DERECHO. 


\section{VENEZUELA 2002: CRISIS POLÍTICA Y DERECHO*}

POR

ROGELIO PÉREZ PERDOMO 1

Profesor del Instituto de Estudios Superiores de Administración Caracas

Los acontecimientos de 2002 en Venezuela han sorprendido a propios y extraños. En abril, el Presidente de la República fue depuesto y reestablecido 48 horas después. En diciembre un paro general se ha prolongado por semanas, deteniendo casi completamente la producción petrolera y la mayor parte de la actividad productiva del país. La mayor parte de las casas y centros comerciales cerraron y una parte importante de la población se abstuvo de hacer compras navideñas. Son acontecimientos extraordinariamente importantes, dada la estructura económica y la tradición cultural venezolana. Enormes multitudes salen frecuentemente a la calle en las principales ciudades del país manifestando en contra del Presidente.

En ambos casos se trata de poner fin al gobierno del Teniente Coronel Hugo Chávez; electo en diciembre de 1998 y electo de nuevo, después de un cambio radical en la Constitución, en julio de 2000. Estos intentos no corresponden a las vías que la constitución de 1999 estableció para la sustitución del Presidente de la República. Estas vías son la elección de un nuevo presidente, en 2006, o el referéndum revoca-

* Tenemos la satisfacción de publicar este artículo, que ha llegado a la redacción de nuestra Revista, enviado por Graciela Soriano de García-Pelayo, Presidenta de la Fundación Manuel García-Pelayo y viuda del insigne constitucionalista.

1 El presente artículo se escribe en Caracas, en medio de un paro cívico que ha llevado al cierre de las instituciones educativas. El apoyo bibliográfico será necesariamente limitado. 
torio en 2003, según entiende Chávez. Según el gobierno, la oposición se ha apartado de la Constitución y debe ser sometida. Según la oposición, el régimen de Chávez se convirtió en una dictadura y el Presidente carece de legitimidad para continuar gobernando. El propósito de este artículo es explicar la proveniencia de esas dos percepciones tan radicalmente diferentes a la luz del derecho y de la teoría de la democracia.

La extrema inestabilidad política de Venezuela en 2002 es aún más excepcional si se mira a la historia del país. Desde 1958 fue una democracia estable, configurada como un sólido sistema de partidos. Era una democracia muy característicamente latinoamericana, montada en un sistema económico-social desigualitario y con un sistema jurídico que no garantizaba los derechos de los grupos sociales desfavorecidos ${ }^{2}$. En las décadas de 1980 y 1990 la economía tuvo fuertes tendencias recesivas; la escasez de recursos fiscales y la deuda externa afectó el funcionamiento del Estado. Para 1989 la «ilusión de armonía" que caracterizaba el sistema político-social había terminado ${ }^{3}$. La década de 1990 fue de debilitamiento de los partidos, de crecimiento de la delincuencia violenta y los escándalos de corrupción. Se trataba de una democracia en crisis ${ }^{4}$.

Es en ese contexto que inicia su carrera política Hugo Chávez. En 1992, siendo un oficial de baja graduación, encabezó un intento de golpe de estado que fue militarmente un fracaso, pero que puso en evidencia la insatisfacción de la mayoría de la población venezolana con el sistema político. En 1998 fue electo presidente con claro respaldo popular. Su ambicioso programa incluía refundar la República y relegitimar los poderes públicos.

2 G. O'DONNELL: "Polyarchies and the (Un)Rule of Law in Latin America". Méndez, O'Donnell \& Pinheiro (eds.): The (Un)Rule of Law and the Underprivileged in Latin America, University of Notre Dame Press, Notre Dame, 1999. R. Pérez PERDomo, "Venezuela 1958-1999: El derecho en una democracia renqueante». Friedman, Pérez Perdomo \& Fix Fierro (eds.): Derecho y culturas jurídicas latinas de Europa y América en tiempos de globalización, Universidad Nacional Autónoma de México, 2003 (en prensa).

3 M. NAím \& R. PIÑANGO: «Introducción: las terribles simplificaciones». M. Naím \& R. Piñango (eds.): El caso Venezuela/ Una ilusión de armonía, Ediciones IESA, Caracas, 1984.

4 M. KornblitH: Venezuela en los 90/ Las crisis de la democracia, Universidad Central de Venezuela \& Ediciones IESA, Caracas, 1998. R. Pérez Perdomo: "Corruption and political crisis". Goodman, Forman, Naim, Tulchin \& Bland (eds.): Lessons of Venezuelan Experience, The Woodrow Wilson Center Press \& John Hopkins University Press, Baltimore \& London, 1995. 
No nos corresponde analizar la personalidad de Chávez. Baste indicar que es un personaje carismático, que gusta de ejercer personalmente el poder político, autoritario, con verbo encendido y una retórica que usa los lugares comunes de la izquierda de 1960. No muestra ninguna capacidad para la negociación, preocupación por la administración ni tampoco se detiene por encontrar obstáculos jurídicos para su acción. Despierta grandes pasiones. Sus enemigos no vacilan en verlo como un loco y una personalización del mal, mientras comanda gran lealtad personal de sus amigos.

Este trabajo está dirigido a analizar los elementos jurídico-constitucionales de la crisis de 2002. En la primera parte, analizaremos la relación de las acciones de Chávez con las constituciones. En la segunda, describiremos su pérdida de popularidad y legitimidad en 2002.

\section{CHÁVEZ, LA CONSTITUCIÓN Y LA BICHA}

No hay duda que Chávez tiene una relación curiosa con las constituciones. En 1992 insurgió en armas contra un gobierno debidamente electo según las reglas de la Constitución de 1961. En 1999, cuando le correspondió jurar que gobernaría conforme a las reglas constitucionales, aprovechó el ritual político para llamar moribunda a la Constitución. Nunca supimos si había realmente cumplido lo que el ritual político exigía.

Un punto central en su programa de gobierno era llamar una asamblea constituyente para que ésta hiciera los cambios políticos radicales que él mismo no definía. La principal dificultad para convocar una asamblea constituyente es que tal procedimiento no estaba previsto en la Constitución de 1961 como mecanismo de cambio constitucional. Sin embargo, en el ordenamiento jurídico venezolano existía la amplia posibilidad de convocar referenda con propósitos diversos (Ley Orgánica del Sufragio). La extinta Corte Suprema de Justicia (Sala Político Administrativa, 19-01-99) decidió que un referéndum que preguntara a la población si deseaba convocar una asamblea constituyente para cambiar la Constitución estaba de acuerdo con los principios democráticos. La Corte Suprema, en una interpretación bastante libre de la Constitución, permitió así que Chávez adelantara un proyecto político que se presentaba como radical. Chávez tenía en ese momento una clara mayoria en la población. La interpretación flexible de la Corte evitó un desconocimiento completo del orden constitucional. 
En una decisión posterior, la Corte Suprema (Sala Político Administrativa, 18-03-99) no aceptó que las bases del proceso comicial para la convocatoria fueran delegadas al Presidente de la República y obligó a que éste detallara de antemano las características de la asamblea constituyente y la manera de elegirla. De esta manera, la Corte Suprema obligó a Chávez a poner sobre la mesa las cartas que él deseaba guardar bajo la manga. El referéndum se celebró el 25-04-99.

Los miembros de la Asamblea Nacional Constituyente fueron electos el 25-07-99. conforme a las reglas previamente adoptadas. Chávez logró una abrumadora mayoría. La asamblea produjo la Constitución nacional, que aprobó el 17-11-99. En el referéndum del 15-12-99 fue aprobada con el 72 por ciento de los votos afirmativos. Cabe mencionar que la abstención fue del 56 por ciento.

La Constitución de la República Bolivariana de Venezuela com. porta varias innovaciones, comenzando por el cambio de nombre de la República, que pasó a ser "bolivariana". El cambio de nombre no es insignificante, como pasamos a analizar.

La Constitución, como texto, puede tener varias lecturas o significados sociales. Los abogados vemos en ella un conjunto de principios y normas que presiden el ordenamiento jurídico: todas las demás leyes y decisiones le están subordinadas. Para los interesados en política, la Constitución establece las reglas del juego político: la manera como son electas las personas que desempeñarán las altas funciones del Estado, los requisitos y procedimientos de la elección, los límites del poder de cada organismo o funcionario, los derechos y garantías de los ciudadanos. Estos dos significados de la Constitución son cercanos y van en la misma dirección de limitación del poder público en general y de definición de las atribuciones de quienes lo ejercen. Cuando se habla de "gobierno constitucional" fundamentalmente nos referimos al tipo de gobierno o régimen político en el cual los poderes de los altos funcionarios del Estado están limitados por los poderes y atribuciones de los otros. La expresión es equivalente a la de "Estado de derecho", aunque generalmente esta última parece incluir también la idea de que los ciudadanos tienen unos derechos consagrados constitucionalmente cuya observancia el poder público debe respetar y garantizar. Implica también que hay una revisión judicial efectiva de los actos del poder público para garantizar el cumplimiento del principio de legalidad y los derechos de los ciudadanos.

Para Chávez estos significados de la Constitución son poco relevantes. Él parece afincarse en otro significado posible: la Constitución 
como expresión de un proyecto político. La edición masiva del texto constitucional se hizo en un pequeño libro azul que Chávez lleva en el bolsillo y que con frecuencia blande en sus largos programas televisivos. La llama "la bicha". En el lenguaje coloquial venezolano "bicho" es un animal que puede causar daño. Cuando se dice de alguien que es un bicho, se implica que es peligroso y malvado. Es por esto que Chávez gustaba de amenazar a sus enemigos con «la b'cha».

En la tradición política venezolana, la atención que se preste a la Constitución no necesariamente significa que exista un estado de derecho o gobierno constitucional. Por ejemplo, el general Juan Vicente Gómez gobernó bajo las constituciones de 1909, 1914, 1925, 1928, 1929 y 1931 . Más propiamente, gobernó con ellas. Él y sus colaboradores fueron unos entusiastas de las reformas constitucionales. Esto muestra que prestaban atención al texto constitucional, aunque nadie sostendría hoy que se trataba de un Estado de derecho, cualquiera que fueran las virtudes o defectos de ese régimen. No había ningún deseo de limitar el poder de quienes ejercian el poder político y de establecer cauces legales para el ejercicio de éste. Este rasgo no es exclusivamente venezolano. Los gobernantes autoritarios latinoamericanos han propiciado siempre reformas constitucionales. Pinochet cambió la constitución de Chile, Fujimori la del Perú.

El cambio de nombre de la tradicionalmente denominada República de Venezuela, por el de República Bolivariana de Venezuela, tiene el significado de destacar el carácter de la Constitución como instrumento político. El movimiento político fundado por Chávez se denominaba originariamente "bolivariano" y él ha continuado usando ese adjetivo para designar su movimiento político. Naturalmente hay una ambigüedad en el adjetivo "bolivariano" pues Bolívar es el héroe nacional. El resultado es que todo aquel que no sea "bolivariano" (en el sentido de partidario de Chávez), no es realmente venezolano o ciudadano. La oposición no puede ser aceptada. Los opositores son descalificados como "oligarcas", "escuálidos", "corruptos" o solidarios de los corruptos. Están excluidos de la República.

En este contexto el análisis del contenido de la Constitución de 1999 no es especialmente importante. El régimen lo ha entendido así. Hay varias diferencias importantes entre el texto aprobado en referéndum el 15-12-99 y el publicado en la Gaceta Oficial el 30-12-99. Aun cuando el Fiscal General solicitó a la Sala Constitucional del Tribunal Supremo que determinara cuál era el texto válido, el Tribunal no ha considerado necesario pronunciarse. 
El texto constitucional como tal es considerablemente largo (350 artículos vs. 252 de la Constitución de 1961), con cambio en la estructuras y nombres. El Poder Legislativo pasa a ser unicameral (ahora denominado Asamblea Nacional). El Poder Judicial pasa a estar presidido por el Tribunal Supremo de Justicia (antes Corte Suprema de Justicia), que asume también las tareas del antiguo Consejo de la Judicatura, que desaparece. El poder público se configura en cinco ramas. Además de las tres tradicionales, se agrega el Poder Ciudadano y el Electoral. La lista de derechos se alarga. Se mantiene la idea de un Estado que interviene en la actividad económica y que es considerablemente centralizado, revirtiendo la tendencia a la descentralización que mostró gran fuerza en la década de 1990.

Los cambios textuales que reflejan mejor el cambio político se concentran en el Poder Ejecutivo nacional. Lo primero es que el período presidencial pasó a 6 años, con la posibilidad de reelección inmediata por una vez (artículo 230). La Constitución de 1961 establecía un período de 5 años, sin reelección inmediata. La reelección era posible sólo después de 10 años de haber cesado como presidente. El Presidente puede recibir la facultad de legislar en lugar de la Asamblea Nacional si ésta lo habilita, estableciendo las directrices, propósitos y el marco de las materias que delega (artículo 203, in fine). La Constitución de 1961 limitaba la legislación delegada a medidas económicas y financieras (artículo 190, 8). La Constitución derogada requería que la Cámara del Senado autorizara los ascensos de los altos oficiales (artículo 150, 5), mientras que la Constitución de 1999 deja esa tarea enteramente en manos del Presidente de la República (artículo $236,6)$.

Para comprender la consolidación del poder de Chávez, el proceso de cambio de Constitución es más importante que el texto constitucional mismo. Durante 1999 la Asamblea Constituyente disolvió el Congreso Nacional y designó una comisión de intervención de la administración de justicia que emprendió la depuración del cuerpo de jueces. La propia Corte Suprema justificó las decisiones al reconocer que la Asamblea Constituyente ejercía un poder originario, es decir, no estaba vinculada por la Constitución de 1961. Luego designó provisionalmente los integrantes del Tribunal Supremo de Justicia.

Las elecciones para el nuevo cuerpo legislativo unicameral, denominado ahora Asamblea Nacional, fueron largamente favorables a los partidarios de Chávez. Estos estaban agrupados en dos partidos: el Movimiento Quinta República (MVR), fundado por el propio Chávez; y el Movimiento al Socialismo (MAS). 
El control de la Asamblea Nacional permitió designar como definitivos los magistrados del Tribunal Supremo, haciendo una depuración de los magistrados que habían mostrado alguna independencia respecto a lo esperado por el poder político, pero permitiendo el ingreso de algunos magistrados vinculados a los partidos de oposición como parte del acuerdo para elegir los magistrados con mayoría calificada. La Asamblea designó a personas claramente comprometidas con Chávez como Fiscal General, Contralor General y Defensor del Pueblo. En resumen, prácticamente todas las posiciones del Estado fueron ocupadas por personas claramente vinculadas al Presidente en el curso del año 2000.

A pesar que los partidarios de Chávez constituían una sólida mayoría en la Asamblea Nacional y controlaban todos los organismos públicos, y que los principales partidos de oposición aparecían débiles y desconcertados, existía la percepción que el gobierno no avanzaba en los cambios que había prometido. Como una manera de poner mayor dinamismo a su gestión, Chávez solicitó y obtuvo de la Asamblea Nacional una amplia autorización para legislar en las materias más diversas en noviembre de $2000^{5}$. En otras palabras, a finales del 2000 y comienzos del 2001, Chávez parecía haber concentrado todos los poderes públicos y no tener limitación alguna para el ejercicio del poder político.

Hubo también una importante innovación en la manera de ejercer el poder. La mayor parte de las decisiones se anunciaban -e incluso parecían tomarse- en el extenso programa de televisión llamado Aló Presidente. Allí ante las cámaras de televisión, recibía llamadas del público, atendía y resolvia problemas individuales, designaba o destituía ministros y altos funcionarios, y establecía políticas públicas. No vacilaba en atender personalmente todos los asuntos, aun aquellas que teóricamente eran competencia de otros funcionarios. Es natural que esta enorme concentración de poder prácticamente tendiera a paralizar el funcionamiento del Estado.

No hay duda que el poder de Chávez podía ser llamado democrático en el sentido de haber sido electo Presidente de la República en diciembre de 1998, bajo la Constitución de 1961, y electo de nuevo en julio de 2000. Su popularidad era muy alta. Entre el 70 y 80 por ciento de los venezolanos aprobaba su gestión. Pero no se trataba de una

5 Ley que autoriza al Presidente de la República para dictar decretos con fuerza en la ley en las materias que se delegan, del 13-11-00. 
democracia liberal, o respetuosa de las reglas de derecho y de las minorías. El propósito no era que el Estado funcionara como un sistema de pesos y balanzas para garantizar de esa manera los derechos de los ciudadanos. Al contrario, la idea era de concentrar todo el poder en manos de Chávez y sus partidarios. La selección de magistrados del Tribunal Supremo, del Fiscal, del Contralor, Defensor del Pueblo y, en general, de todos los cargos del Estado, obedeció a esta lógica de garantizar la lealtad política por encima de la competencia profesional o el pluralismo ideológico.

En resumen, el origen del poder de Chávez fue electoral y durante los años 1999 y 2000 contó con un amplio apoyo de la población. La manera de ejercer el poder no fue democrática: su propósito fue concentrar todo el poder en su persona y no reconocer una oposición. El derecho y la Constitución no eran concebidos como límites para el ejercicio del poder ni como garantía de libertades y derechos individuales. No era una democracia liberal moderna ${ }^{6}$. Su ascendiente era el personalismo político latinoamericano ${ }^{7}$ y el proyecto y lenguaje bastante cercano al de Fidel Castro.

\section{EL OTOÑO DEL PATRIARCA}

En el año 2001, el poder omnímodo empezó a mostrar sus debilidades. El intento de penetrar en las instituciones encontró el rechazo que probablemente Chávez y muchos observadores no esperaban. Uno de estos casos fue la educación privada. En Venezuela, debido a la baja calidad de la educación pública, la privada es muy importante. Lo primero que hace una familia cuando sobrepasa el nivel de subsistencia es poner a los hijos (e hijas) en colegios privados. Esto es cierto también para personas de bajos ingresos, que viven en los barrios. Alli existen las escuelas de Fe y Alegría, una organización católica, con una gigantesca red de institutos educativos. La educación en estas escuelas no es gratuita, pero los pagos son bastante bajos. El gobiernó dictó el Decreto 1011 (publicado el 31-10-00). El propósito era controlar la educación privada. La motivación ideológica no se disimula-

6 R. DaHL: Democracy and Its Critics, Yale University Press, New Haven, 1989.

7 G. Soriano de García Pelayo: El personalismo político hispanoamericano del siglo XIX. Criterios y proposiciones metodológicas para su estudio, Monte Ávila, Caracas, 1996. 
ba. Se establecieron inspectores con enormes poderes, que podían hasta destituir los directores de cualquier colegio. El gobierno suprimió el subsidio a los institutos privados, incluidas las organizaciones católicas.

Los opositores al Decreto 1011 lograron convocar manifestaciones de protesta considerablemente grandes. Chávez enfrentó igualmente a la Iglesia Católica. El conflicto fue prolongado y en un momento álgido varias bombas de baja potencia fueron colocadas en varios templos católicos de Caracas por partidarios del gobierno.

Los chavistas sufrieron otro fracaso importante cuando intentaron controlar la Universidad Central de Venezuela. Esta es la universidad más importante del país y como universidad autónoma, elige sus propias autoridades. Los candidatos chavistas fueron derrotados. Luego, un grupo de estudiantes chavistas "tomaron" (ocuparon permanentemente) la sala de reuniones del Consejo Universitario y las oficinas del Rector. El propósito enunciado era lograr la convocatoria de una "constituyente universitaria" que renovara la educación. El propósito real no disimulado era sustituir al Rector y otras autoridades electas por personas más cercanas al gobierno. Chávez expresó su apoyo a los llamados "tomistas". La comunidad universitaria expresó su rechazo en multitudinarias manifestaciones hasta que los tomistas abandonaron los locales ocupados y enfrentaron sanciones académicas.

El conflicto más significativo se dio por el control de la principal central sindical, la Confederación Venezolana de Trabajadores. Apoyado en la crítica a la manera poco democrática como se escogian los dirigentes laborales y en un referéndum en la materia, Chávez impuso la democratización en la elección de los dirigentes sindicales. Los dirigentes fueron electos democráticamente y los candidatos chavistas resultaron perdedores. El gobierno no reconoció haber sido derrotado, descalificó los líderes electos e intentó dividir el movimiento sindical.

Progresivamente Chávez se enemistó con los medios de comunicación social, los cuales les eran inicialmente favorables. Se quejaba de que los medios no destacaban los aspectos realmente importantes de sus alocuciones o de que le atribuyeran afirmaciones que él no había hecho. Esto obligaba a los periodistas a reproducir literalmente las afirmaciones del presidente y a polemizar con él.

En resumen, diversas elecciones o acciones en ámbitos restringidos, mostraron que el poder de Chávez estaba encontrando resis- 
tencias en distintos ámbitos institucionales. Chávez no se daba por aludido y más bien agudizaba su retórica revolucionaria. Los resultados prácticos no podían ser menos esperanzadores. La retórica anti-empresarial detuvo las inversiones y aumentó el desempleo y la pobreza. La delincuencia violenta repuntó notablemente. La respuesta fue la modificación del Código Orgánico Procesal Penal loriginariamente publicado en 1998 y reformado parcialmente en 2000 y 2001) para hacerlo más represivo. Más grave aún, escuadrones de la muerte empezaron a actuar en varias ciudades ${ }^{8}$. Chávez se presentaba como el campeón de los pobres, pero la pobreza aumentaba y las condiciones de vida de los pobres, sobre todo por el aumento de la violencia en los barrios, se deterioraba.

La enorme concentración de poder en manos de Chávez empezó a mostrar su costo. Él aparecía como responsable de lo que ocurría o dejaba de ocurrir. Su popularidad comenzó a bajar y las resistencias comenzaron a hacerse mucho más fuertes. Al final de 2001 el inmenso poder y a la vez la debilidad de Chávez se hicieron visibles. En noviembre de 2001 produjo 49 decretos leyes en materias tan importantes como petróleo, gas, propiedad de la tierra, pesca, y costas. Este conjunto legislativo, que está formalmente vigente, resultó predeciblemente polémićo. Los decretos-leyes afectaban a casi todos los sectores de la sociedad venezolana y fueron producidos saltando la consulta que la teoría de la legislación recomienda y que en Venezuela es exigido por la Constitución en el artículo 211. La ley habilitante del 13-11-00 estableció (artículo 4) la obligación de informar sobre la legislación delegada a una comisión de la Asamblea Nacional al menos diez días antes de la publicación. Chávez no cumplió esos requerimientos. Ningún grupo afectado fue consultado u oído, ni la Asamblea fue informada, generando así la mayor resistencia.

La oposición comenzó por pedir diálogo y rectificación. Chávez respondió con agresión y radicalización, lo cual llevó a que el sector moderado de su partido pasara a la oposición. El 10-12-01, un paro general de actividades por un día, convocado por la central obrera y la más importante organización empresarial, fue un éxito rotundo y, en cierto sentido, marcó el comienzo de la crisis política. Fue el total desprecio de Chávez por estas modestas peticiones el hecho desen-

8 R. Pérez Perdomo \& P. Monteferrante: «Inseguridad y COPP: ¿Qué se discute? ¿Qué está en juego?", Debates IESA, vol. 3, \# 1, Caracas, 2001. 
cadenante de una oposición más decidida y, en definitiva, de la crisis política.

La política exterior de Chávez fue igualmente polémica. La relación con Cuba fue más que un acercamiento. Chávez y Fidel Castro desarrollaron una sólida amistad que se tradujo en una intensificación de los intercambios. A la venta del petróleo con facilidades de pago, Cuba respondió enviando un número importante de entrenadores deportivos, médicos y asesores de seguridad. También la relación con la guerrilla de Colombia se intensificó. Los gobernantes de Irak y Libia pasaron a ser amigos de Chávez. Paralelamente se produjeron tensiones con Estados Unidos y Colombia, los más importantes socios económicos del país.

A comienzos de 2002, Chávez lucía debilitado. El primer trimestre de 2002 fue un momento de grandes concentraciones populares, organizadas tanto por la oposición como por el gobierno. Estas concentraciones mostraron que mientras la participación en las concentraciones de la oposición eran espontáneas, los chavistas requerian trasladar personas de distintas partes del país y pagar a los manifestantes. Claramente la oposición había pasado a ser una mayoría muy activa.

El discurso de Chávez se tornó más amenazador. Con frecuencia hacía referencia que la revolución estaba armada. Comenzó a usar con asiduidad el uniforme militar.

Los "círculos bolivarianos" comenzaron a mostrar su cara violenta. Estos "círculos» eran aparentemente grupos para la movilización popular. En la medida en que se incrementó el conflicto político fueron convertidos en bandas armadas que atacaron a parlamentarios de la oposición, medios de comunicación, obras teatrales de humor político y personas individuales.

PDVSA, la empresa petrolera estatal, se convirtió también en parte de la lucha política. Es importante señalar que desde la nacionalización de la industria petrolera en 1975, los partidos políticos habían respetado el acuerdo tácito de no interferir con los profesionales que dirigían la empresa y de haberla exceptuado de sus políticas clientelistas. Chávez no se sintió vinculado por el acuerdo. En un intento de tener un mejor control político designó sucesivamente tres presidentes en tres años. Uno de ellos, el General Lameda, prefirió renunciar junto con el directorio, en vez de continuar embarques petroleros a Cuba a pesar que ese país no estaba pagando sus facturas. 
En abril de 2002 confluyeron todos los motivos de descontento. La defensa de la empresa petrolera ante el empuje para convertirla en un apéndice político del Estado estuvo en primera plana. Se convocó a un nuevo paro general que fue seguido también por la industria petrolera. La oposición realizó grandes concentraciones públicas. Una de ellas, notablemente gigantesca, decidió marchar al Palacio de Miraflores, lugar de las oficinas del Presidente, para solicitar su renuncia. El Presidente llamó a los militares principales para detener la multitud, pero éstos no respondieron. En un puente cercano al palacio presidencial, los partidarios de Chávez dispararon en contra de la multitud. El incidente causó dos decenas de muertos y muchos heridos. Chávez intentó censurar los medios de comunicación para que no transmitieran más noticias. Los jefes militares anunciaron primero que no obedecían al Presidente, luego el general de más alta graduación, Lucas Rincón, anunció que el Presidente había aceptado renunciar. El 12-04-02 el dirigente empresarial Carmona, anunció que asumía la Presidencia Provisional, disolvió la Asamblea Nacional y destituyó los magistrados del Tribunal Supremo. La erección de Carmona en una especie de gobernante absoluto disgustó a quienes se suponían sus aliados, a los militares y la comunidad internacional. Hubo también una pequeña reacción popular violenta. Un día después Chávez fue restituido a la presidencia.

Las acciones de Carmona corresponden a los antecedentes de los gobiernos de facto en América Latina, seguramente ejecutados con torpeza política. Lo que muestra su fracaso es que ha habido un cambio epocal importante. Aun cuando su intención fuera de restablecer la democracia y el Estado de derecho, en la práctica se erigía en dictador, desconociendo el proceso constitucional. Fue esto lo que resultó inaceptable.

El regreso de Chávez fue dramático. Pidió perdón y prometió reconciliación. Su estilo polémico hizo que esas intenciones fueran rápidamente olvidadas. El gobierno hizo los mayores esfuerzos por encubrir a quienes dispararon contra la multitud el 11-04-02 ("los asesinos de Puente Llagunon) y continuó la agresión contra los medios de comunicación y periodistas.

La constitución de 1999 requiere que los oficiales generales, asi como los altos funcionarios del Estado, sean sometidos a antejuicio en el Tribunal Supremo como requisito para un juicio penal. El Fiscal General solicitó el antejuicio de los oficiales generales implicados en los acontecimientos de abril, por rebelión militar. Sólo fue exceptuado el General Rincón, quien fue designado Ministro de la Defensa. EI 
Presidente del Tribunal Supremo, partidario de Chávez, designó sucesivamente dos ponentes que propusieron que se autorizara el juicio (agosto 2002). Se esperaba que la tercera ponencia fuera favorable a los militares. Chávez amenazó a los magistrados del Tribunal Supremo con una reacción popular. Efectivamente los grupos violentos atacaron al Tribunal Supremo.

El caso tiene el enorme interés juridico de que el Fiscal General acusó por rebelión militar, un delito que requiere "alzarse en armas". El Tribunal Supremo consideró que no había alzamiento en armas pues lo que ocurrió fue que los generales se negaron a mover los tanques $y$ aviones para detener una manifestación civil. Además, por un defecto de técnica legislativa, el delito fue formulado en el Código de Justicia Militar sin que le corresponda una pena específica. En una votación dividida (11-8) la Sala Plena no autorizó el juicio a los generales. El Fiscal General probablemente conocía las dificultades de solicitar enjuiciamiento por rebelión militar. Uno puede suponer que prefirió acusar por ese delito, en vez del de desobediencia, que correspondía más a los hechos, pues tal acusación necesariamente abría el debate sobre cuál fue la orden de Chávez y si la movilización militar era legítima frente a una manifestación popular desarmada y pacífica.

\section{LA FUERZA Y LOS LÍMITES DEL DERECHO}

En el momento que esto se escribe el conflicto político se mantiene. Chávez ha perdido la capacidad de impulsar cualquier proyecto político y hasta la más simple de gobernar. No sólo carece de respaldo en ninguna de las fuerzas organizadas, sino que éstas (sindicales, empresariales, profesionales, la Iglesia Católica, entre otras) lo oponen abierta y activamente. Al parecer sólo ha logrado neutralizar a los militares que están de su lado o no arriesgan levantarse en armas. La oposición ha organizado frecuentes manifestaciones populares. Desde el 02-12-02, existe un paro cívico que ha paralizado económicamente al país, mientras los opositores realizan grandes manifestaciones públicas en las calles de las principales ciudades. Cada noche, en distintas áreas urbanas, hay también manifestaciones ruidosas. Los manifestantes piden la salida de Chávez. Las fuerzas del gobierno han perdido la capacidad de organizar manifestaciones populares grandes y sólo intentan amedrentar usando la violencia.

Los opositores han usado abundantemente el derecho. Con frecuencia logran amparos que limitan temporalmente la acción del 
gobierno y, en ocasiones, como en el caso de los oficiales generales enjuiciados, Chávez ha percibido que limita su capacidad de imponerse sobre sus opositores. En diciembre 2002 hizo un llamado público para que los militares y los funcionarios públicos no obedecieran a los jueces sino a sus decretos. El Fiscal General, su aliado político, se sintió obligado a hacer el llamado contrario, de obediencia a las órdenes judiciales. Sin embargo, los jueces han actuado en todas las direcciones. La propia Sala Constitucional del Tribunal Supremo acordó un amparo que intentaba poner fin al paro cívico en el ámbito petrolero (17-1202) que no tuvo otro efecto que aumentar la acción represiva del gobierno sin ningún resultado inmediato.

Los puntos de discusión están muy vinculados a maneras de entender el derecho. La oposición no espera ni promueve una intervención militar. Ha solicitado un referéndum consultivo en el cual se pregunta si el elector está de acuerdo en pedirle al Presidente que renuncie. Tal referéndum ha sido acordado por el Consejo Nacional de Elecciones para el 02-02-03, pero el gobierno trata de obstaculizarlo. También circula la idea de una enmienda constitucional que abrevie el período presidencial a cuatro años y convoque a elecciones. La idea más reciente es la convocatoria de una asamblea constituyente. Estas salidas electorales no se excluyen entre sí y cuentan con clara mayoría en las encuestas de opinión. Es probable que el referéndum incluya más de una pregunta. Por su parte, Chávez bloquea cualquier salida electoral, excepto un referéndum revocatorio en agosto de 2003. Como la organización de un referéndum cuesta dinero y éste debe ser aprobado por la Asamblea Nacional, controlada por Chávez, el bloqueo puede ser efectivo.

La oposición tiene motivos para pensar que el planteamiento de Chávez es sólo una manera de ganar tiempo. Su argumento es formalista en extremo: la Constitución no permite una salida electoral antes de cumplir la mitad del período y el referéndum consultivo sólo disfraza un referéndum revocatorio, por lo cual no debe convocarse. Dado el total desprecio de Chávez por el Estado de derecho, el argumento carece de credibilidad. La fortaleza de Chávez, que era su invocación a la democracia y al respaldo popular, se ha revertido, y es ahora la fortaleza de la oposición. Ésta lo que pide es "vamos a contarnos".

Es importante observar que la situación de alta tensión se mantiene con relativamente pocos encuentros violentos. Llama la atención que Chávez no haya decretado "estado de excepción» (Constitución, artículo 337) o de "conmoción interior" (artículo 338, § 3). Seguramente la convicción que de todas maneras no va a ser obedecido y que 
el estado de excepción pondrá en mayor evidencia su debilidad, ha evitado que tome tales medidas. De todas maneras, tiene constitucionalmente tales restricciones que el estado de excepción no hace mucha diferencia. Los grupos violentos del gobierno actuan con relativa moderación, probablemente porque acciones más intensas pueden provocar una reacción militar en contra del gobierno. Por su parte, la oposición es explícitamente no violenta.

La situación puede ser descrita como de ingobernabilidad, pero en la práctica existe un cierto orden. La explicación puede estar en la descentralización del país. Desde el comienzo de la década de los 90 los venezolanos comenzamos a elegir a los gobernadores y alcaldes. Estos funcionarios se distribuyen en todo el espectro político y tienen mucho mayor contacto con sus electores. La mayor parte de las fuerzas policiales corresponden a estos ámbitos. En Caracas el Alcalde Mayor (con competencias similares a las de un gobernador), el Gobernador del Estado Miranda (al cual corresponde el Este de Caracas), y los alcaldes de tres de los cinco municipios que integran el área metropolitana son de la oposición. La coexistencia de estos distintos poderes no ha ido sin dificultad. Un conflicto reciente importante ha sido por el control de la Policía Metropolitana (que corresponde al Alcalde Mayor), que el Ministro del Interior trató de poner bajo su control sin lograrlo.

Sin embargo, una salida pacífica se muestra elusiva. Chávez ha sido acusado de varios delitos, pero el enjuiciamiento requeriría un Fiscal General dispuesto a investigar seriamente o un Tribunal Supremo dispuesto a tomar la situación con liderazgo. Ninguna de las dos condiciones existen. El Fiscal General es claramente leal a Chávez. El Tribunal Supremo está profundamente dividido. Por otra parte, el juicio ál Presidente requiere también la autorización de la Asamblea Nacional, todavía controlada por Chávez. En otras palabras, la solución tradicional vía intervención militar parece descartada, pero a la vez la solución siguiendo las rutas constitucionales requieren que Chávez o los chavistas no pongan obstáculos insuperables.

El elemento nuevo en la crisis política venezolana es la intervención muy activa de la comunidad internacional, representada en este caso por la Organización de Estados Americanos ${ }^{9}$. En abril 2002,

9 Aun cuando una novedad en Venezuela, la intervención de la OEA, fúe muy importante en el Perú, al final del período de Fujimori. Claramente es una tendencia en América Latina. 
ante el golpe de estado, la OEA respaldó al gobierno de Chávez y es indudable que tal respaldo tuvo un impacto en la política interna. Cuando posteriormente el conflicto político se mantuvo, el Secretario General de la OEA César Gaviria, prácticamente se ha mudado a Caracas donde preside la Mesa de Negociación y Acuerdo. Esta mesa es la única instancia formal de diálogo entre el gobierno y la oposición, pero no ha producido todavía ningún acuerdo importante. En diciembre 2002, el gobierno de Venezuela buscó una nueva declaración de apoyo en la OEA, pero esta vez la resolución fue de respaldo a la labor del Secretario General y un llamado al gobierno a entenderse con la oposición y respetar los medios de comunicación.

La presencia de Gaviria en Caracas probablemente es uno de los elementos que ha disuadido al gobierno de usar más intensamente a los círculos violentos o la represión abierta, pero Gaviria carece de poder para imponer una solución. Cada parte juega a la fatiga o el desgaste de la otra. Gobierno y oposición desean mostrar a la otra parte como responsable de la paralización y las penurias que la población ha comenzado a experimentar. Hasta ahora, la batalla parece a favor de la oposición.

La ironía es que el gobierno de Chávez justificó la legitimidad de la "revolución" que desea implantar en el apoyo popular. Era una justificación democrática. A la vez demostraba una completa falta de respeto por la idea del estado de derecho y las limitaciones que implican el gobierno constitucional, un elemento central de la democracia moderna o democracia liberal. El hecho es que en 2002, el gobierno ha perdido esa mayoría y se enfrenta a una oposición activa que no está dispuesta a sufrir una revolución socialista. La actitud democrática sería la renuncia. Sin embargo, Chávez se resiste invocando como argumento el texto constitucional. Es una posición no creíble, dada su conducta previa. La corriente mayoritaria de la oposición, agrupada en la Coordinadora Democrática, desea mantenerse en el cauce institucional y no propicia la intervención militar. El chasco de abril ha tenido esa clara consecuencia. Por esto vemos un gobierno sin sustento cayendo en cámara lenta.

Cuando esto se escribe, la agonía del régimen de Chávez es también una terrible tensión para la mayoría de la población venezolana. Todavía no sabemos si la transición podrá evitar la intervención militar y la violencia generalizada en las calles. Pero ésa es la esperanza. 